\title{
Outcomes of major complications after robotic anatomic pulmonary resection
}

\author{
Christopher Cao, MBBS, PhD, ${ }^{\mathrm{a}, \mathrm{b}}$ Brian E. Louie, MD,${ }^{\mathrm{c}}$ Franca Melfi, MD, ${ }^{\mathrm{d}}$ Giulia Veronesi, MD, \\ Rene Razzak, MD, ${ }^{\mathrm{c}}$ Gaetano Romano, MD, ${ }^{\mathrm{d}}$ Pierluigi Novellis, MD, ${ }^{\mathrm{e}}$ Neel K. Ranganath, $\mathrm{MD},{ }^{\mathrm{f}}$ and \\ Bernard J. Park, MD
}

\begin{abstract}
Background: There is a paucity of robust clinical data on major postoperative complications following robotic-assisted resection for primary lung cancer. This study assessed the incidence and outcomes of patients who experienced major complications after robotic anatomic pulmonary resection.

Methods: This was a multicenter, retrospective review of patients who underwent robotic anatomic pulmonary resection between 2002 and 2018. Major complications were defined as grade III or higher complications according to the Clavien-Dindo classification. Statistical analysis was performed based on patient-, surgeon-, and treatment-related factors.
\end{abstract}

Results: During the study period, 1264 patients underwent robotic anatomic pulmonary resections, and 64 major complications occurred in 54 patients $(4.3 \%)$. Univariate analysis identified male sex, forced expiratory volume in 1 second, diffusion capacity of the lung for carbon monoxide, neoadjuvant therapy, and extent of resection as associated with increased likelihood of a major postoperative complication. Patient age, performance status, body mass index, reoperation status, and surgeon experience did not have a significant impact on major complications. Patients who experienced at least 1 major complication were at higher risk for an intensive care unit stay of $>24$ hours $(17.0 \%$ vs $1.4 \% ; P<.001)$ and prolonged hospitalization ( 8.5 days vs 4 days; $P<.001)$. Patients who experienced a major postoperative complication had a $14.8 \%$ risk of postoperative death.

Conclusions: In this series, the major complication rate during the postoperative period was $4.3 \%$. A number of identified patient- and treatment-related factors were associated with an increased risk of major complications. Major complications had a significant impact on mortality and duration of stay. ( $\mathrm{J}$ Thorac Cardiovasc Surg 2020;159:681-6)

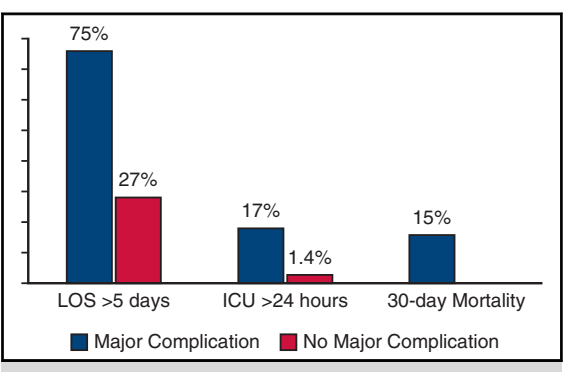

Major complications after robotic pulmonary resections significantly impacts outcomes.

\section{Central Message}

The incidence of major complications after robotic resections was low and associated with a number of identified factors.

\section{Perspective}

With the increasing use of robotic thoracic procedures internationally, there is an urgent need to identify the incidence and outcomes of patients who experience major complications after surgery. The present study represents one of the largest multi-institutional, standardized databases used to date to analyze complication outcomes after robotic anatomic pulmonary resections.

See Commentaries on pages 687 and 689.
Robotic-assisted lung resection (RAL) has emerged as a safe and reproducible alternative to conventional video-assisted thoracoscopic surgery (VATS) or thoracotomy for patients with non-small cell lung cancer (NSCLC). Previous studies have reported the perioperative safety and long-term oncologic efficacy of the robotic approach. ${ }^{1-4}$

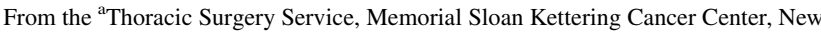
York, NY; ${ }^{\mathrm{b}}$ Department of Cardiothoracic Surgery, Royal Prince Alfred Hospital, Sydney, Australia; ${ }^{c}$ Division of Thoracic Surgery, Swedish Medical Center and Cancer Institute, Seattle, Wash; ${ }^{\mathrm{d}}$ Robotic Multispecialty Center for Surgery Robotic, Minimally Invasive Thoracic Surgery, University of Pisa, Pisa, Italy; ${ }^{\mathrm{e}}$ Division of Thoracic and General Surgery, Humanitas Research Hospital, Rozzano, Milano, Italy; and ${ }^{\mathrm{f}}$ Department of Cardiothoracic Surgery, NYU Langone Health, New York, NY.

This work was funded, in part, by the National Institutes of Health/National Cancer Institute Cancer Support Grant P30 CA008748.
}

Recent trends from the Society of Thoracic SurgeonsGeneral Thoracic Surgery Database (STS GTSD) and the National Cancer Database have demonstrated exponential growth in the use of robotic-assisted approaches for patients with NSCLC. ${ }^{5,6}$ However, despite heightened interest and increased performance of RAL in clinical practice, there

\footnotetext{
Read at the 99th Annual Meeting of The American Association for Thoracic Surgery, Toronto, Ontario, Canada, May 4-7, 2019.

Received for publication Feb 22, 2019; revisions received Aug 21, 2019; accepted for publication Aug 25, 2019; available ahead of print Nov 2, 2019

Address for reprints: Bernard J. Park, MD, Thoracic Surgery Service, Memoria Sloan-Kettering Cancer Center, 1275 York Avenue, Room C-879, New York NY 10065 (E-mail: parkb@mskcc.org).

$0022-5223 / \$ 36.00$

Copyright (c) 2019 by The American Association for Thoracic Surgery https://doi.org/10.1016/j.jtcvs.2019.08.057
} 


$\begin{array}{ll}\text { Abbreviations and Acronyms } \\ \text { ARDS } & =\text { acute respiratory distress syndrome } \\ \text { BMI } & =\text { body mass index } \\ \text { DLCO } & =\text { diffusion capacity for carbon } \\ & \text { monoxide } \\ \text { ECOG } & =\text { Eastern Cooperative Oncology Group } \\ \text { FEV } & =\text { forced expiratory volume in } 1 \text { second } \\ \text { ICU } & =\text { intensive care unit } \\ \text { IQR } & =\text { interquartile range } \\ \text { NSCLC } & =\text { non-small cell lung cancer } \\ \text { PET } & =\text { positron emission tomography } \\ \text { RAL } & =\text { robotic-assisted lung resection } \\ \text { STS GTSD }= & \text { Society of Thoracic Surgeons General } \\ & \text { Thoracic Surgery Database } \\ \text { VATS } & =\text { video-assisted thoracoscopic surgery }\end{array}$

To view the AATS Annual Meeting Webcast, see the URL next to the webcast thumbnail.

is a paucity of robust clinical data on major complications after robotic pulmonary resection.

The primary aim of this study was to identify the incidence of major complications after robotic lung resections for patients with primary lung cancer, according to standardized and predefined criteria. Secondary aims were to identify the patient-, surgeon-, and treatmentrelated factors associated with major complications, as well as the mortality and duration of hospitalization outcomes of these patients during the postoperative period.

\section{METHODS}

This was a multicenter, retrospective review of patients who underwent robotic anatomic pulmonary resection in 4 institutions: Memorial Sloan Kettering Cancer Center, Swedish Medical Center and Cancer Institute, University of Pisa Hospital, and Humanitas Research Hospital. The study was approved by the Institutional Review Board of each participating center, and a data transfer agreement was made to Memorial Sloan Kettering Cancer Center (approval protocol \#17-627). The primary endpoint was major complications during the postoperative period, defined as grade III or higher events according to the Clavien-Dindo classification. ${ }^{7}$ In brief, grade III complications require surgical, endoscopic, or radiologic intervention; grade IV complications are life-threatening and require intensive care unit (ICU) management; and grade V complications result in death. Major complications were included for analysis if the complications occurred within 30 days since the date of operation or during the same admission, whichever was longer. Major complications included pneumonia, prolonged air leak, acute respiratory distress syndrome (ARDS), bronchopleural fistula, cardiac arrhythmias, heart failure, myocardial infarction, empyema, chylothorax, pulmonary embolism, renal failure, and wound infection.

\section{Patient Selection Criteria}

Patients age $>18$ years with biopsy-proven or pathological diagnosis of primary lung cancer who underwent robotic anatomic pulmonary resection were included in our analysis. Patients with adenocarcinomas, squamous cell carcinomas, carcinoid tumors, large cell tumors, and other types of NSCLCs were included, whilst patients with benign lesions and small cell lung cancers were excluded. Anatomic pulmonary resections included segmentectomies, lobectomies, bilobectomies, and pneumonectomies. Patients who underwent wedge resections were excluded from the study cohort. Clinical staging was based on computed tomography of the chest and whole-body positron emission tomography (PET), as well as mediastinoscopy and/or endobronchial ultrasound, according to institutional protocols. Clinical and pathological staging were based on the 8 th edition of the TNM staging system for NSCLC. ${ }^{8}$

\section{Study Variables}

Patient-, surgeon- and treatment-related variables were collected for statistical analysis in relation to major postoperative complications according to a standardized datasheet form. Patient-related factors included age, sex, Eastern Cooperative Oncology Group (ECOG) performance status, body mass index (BMI), percentage of predicted forced expiratory volume in 1 second $\left(\mathrm{FEV}_{1}\right)$, diffusing capacity of the lung for carbon monoxide (DLCO), clinical stage, histopathological type, and tumor site. Surgeon-related factor included experience with $\leq 20$ cases versus $>20$ cases, consistent with previous reports on the learning curve period. ${ }^{9-12}$ Treatment-related factors included neoadjuvant therapy, previous thoracic surgery to the ipsilateral side, extent of anatomic resection (segmentectomy, lobectomy, bilobectomy, or pneumonectomy), duration of the operation from skin incision to skin closure, and completeness of resection (R0, R1, or R2). Clinical outcomes of patients with and without postoperative major complications were compared for postoperative mortality, hospital length of stay, and ICU length of stay.

\section{Statistical Analysis}

Descriptive and comparative analyses were performed in patients who experienced a major postoperative complication and those who did not. For univariate analysis, the $\chi^{2}$ or Fisher's exact test was used to determine significant differences in categorical variables. The Mann-Whitney $U$ test was used to compare the distributions of continuous variables. A significant difference was predetermined to be $P \leq .05$. All statistical analyses were performed using SPSS for Windows version 25 (IBM, Armonk, NY).

\section{RESULTS}

Between November 2002 and April 2018, 1264 consecutively operated patients who underwent robotic anatomic pulmonary resection at one of the participating institutions were included in a centralized database. The median age of the entire cohort was 69 years (interquartile range [IQR], 63-74 years), and the cohort was $44.5 \%$ male. Performance status was reported as ECOG 0 in $73.2 \%$ (807 of 1102), ECOG 1 in 24.8\% (273 of 1102), ECOG 2 in $1.8 \%$ (20 of 1102), and ECOG 3 in $0.2 \%$ (2 of 1102). The median BMI was 26 (IQR, 23-30). The median FEV was $94 \%$ of predicted, and the median DLCO was $80 \%$ of predicted. Clinical staging was reported as stage I in $74.2 \%$, stage II in $16.2 \%$, stage III in $8.6 \%$, and stage IV in $1.0 \%$. A total of 191 cases $(15 \%)$ were performed by surgeons who had previous experience with $\leq 20$ cases. Neoadjuvant chemotherapy or radiotherapy was prescribed in $8.5 \%$ of patients. Histopathology included adenocarcinoma (74.1\%), squamous cell carcinoma $(12.2 \%)$, carcinoid tumors $(6.3 \%)$, large cell carcinoma $(1.3 \%)$, 
and other types of NSCLCs $(6.1 \%)$. Surgical resections included segmentectomy $(8.1 \%)$, lobectomies $(89.7 \%)$, bilobectomies $(1.9 \%)$, and pneumonectomies $(0.3 \%)$. Among the 1264 patients, 1249 had an R0 resection, 13 had an R1 resection, and 2 had an R2 resection. The median duration of operation was 187 minutes (IQR, 151-231 minutes). Eighty-nine patients (7.0\%) underwent conversion to thoracotomy after robotic docking. The postoperative mortality rate for the entire study cohort was $0.6 \%$. The median duration of hospitalization was 4 days (IQR, 3-6 days), and 26 patients (21\%) required a postoperative ICU stay $>24$ hours.

According to predefined criteria for postoperative major complications, 54 patients $(4.3 \%)$ experienced at least 1 major complication, including 52 grade 3 events, 4 grade 4 events, and 8 grade 5 events. These included pneumonia in 14 patients $(1.2 \%)$, prolonged air leak in 12 patients $(0.9 \%)$, ARDS in 8 patients $(0.6 \%)$, bronchopleural fistula in 5 patients $(0.4 \%)$, cardiac arrhythmias in 9 patients $(0.7 \%)$, heart failure in 1 patient $(0.1 \%)$, myocardial infarction in 1 patient $(0.1 \%)$, empyema in 4 patients $(0.3 \%)$, chylothorax in 4 patients $(0.3 \%)$, and pulmonary embolism in 2 patients $(0.2 \%)$. These findings are summarized in Table 1. Univariate analysis identified male sex (63\% vs $44 \%$; $P=.007), \mathrm{FEV}_{1}(86 \%$ vs $94 \%$; $P<.001)$, DLCO $(67 \%$ vs $80 \% ; P=.011)$, neoadjuvant therapy $(16.7 \%$ vs $8.1 \% ; P=.041)$, and extent of resection (segmentectomy vs lobectomy vs bilobectomy vs pneumonectomy; $P=.040$ ) as associated with an increased

TABLE 1. Major postoperative complications after robotic anatomic pulmonary resections for patients with non-small cell lung cancer

\begin{tabular}{lccc}
\hline & \multicolumn{3}{c}{ Grade of complication } \\
\cline { 2 - 3 } & $\begin{array}{c}\text { Grade 3: } \\
\text { severe }\end{array}$ & $\begin{array}{c}\text { Grade 4: } \\
\text { life- } \\
\text { threatening }\end{array}$ & $\begin{array}{c}\text { Grade 5: } \\
\text { lethal }\end{array}$ \\
\cline { 2 - 3 } & $\begin{array}{c}\text { No. of } \\
\text { patients }\end{array}$ & $\begin{array}{c}\text { No. of } \\
\text { patients }\end{array}$ & $\begin{array}{c}\text { No. of } \\
\text { patients }\end{array}$ \\
\multicolumn{1}{c}{ Complication } & $\mathbf{( \% )}$ & $\mathbf{( \% )}$ & $\mathbf{( \% )}$ \\
\hline Pulmonary & & & \\
Pneumonia & $11(0.9)$ & $2(0.2)$ & $1(0.1)$ \\
Prolonged air leak & $12(0.9)$ & $0(0)$ & $0(0)$ \\
ARDS & $5(0.4)$ & $0(0)$ & $3(0.2)$ \\
Bronchopleural fistula & $5(0.4)$ & $0(0)$ & $0(0)$ \\
Empyema & $3(0.2)$ & $1(0.1)$ & $0(0)$ \\
Chylothorax & $4(0.3)$ & $0(0)$ & $0(0)$ \\
Cardiac & & & \\
Pulmonary embolism & $0(0)$ & $1(0.1)$ & $1(0.1)$ \\
Heart failure & $1(0.1)$ & $0(0)$ & $0(0)$ \\
Arrhythmia & $9(0.7)$ & $0(0)$ & $0(0)$ \\
Myocardial infarction & $1(0.1)$ & $0(0)$ & $0(0)$ \\
\hline Renal failure & $1(0.1)$ & $0(0)$ & $0(0)$ \\
Wound infection & $0(0)$ & $0(0)$ & $0(0)$ \\
\hline
\end{tabular}

Three additional mortalities had unknown causes of death and were not listed. ARDS, Acute respiratory distress syndrome.

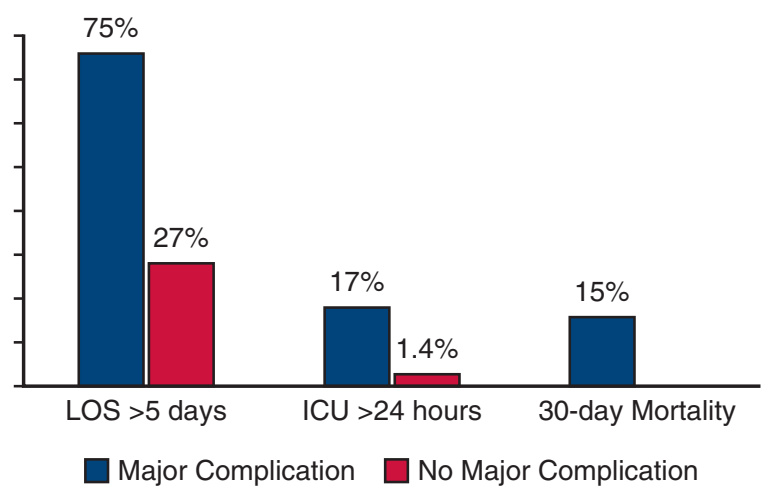

FIGURE 1. Major complications after robotic pulmonary resections are associated with poor outcomes. $L O S$, Length of stay; $I C U$, intensive care unit.

likelihood of a major postoperative complication. The patient's age, performance status, BMI, and reoperation status and the surgeon's experience with $>20$ cases did not have a statistically significant impact on major complications. However, the duration of operation was significantly longer in surgeons with experience with $\leq 20$ cases than in surgeons with experience with $>20$ cases (216 vs 182 minutes; $P<.001$ ). Patients who sustained at least 1 major complication were at significantly greater risk for ICU stay of $>24$ hours $(17.0 \%$ vs $1.4 \%$; $P<.001)$ and prolonged hospitalization $(8.5$ days vs 4 days; $P<.001$ ). Patients who sustained a major postoperative complication had a $14.8 \%$ risk of postoperative death (Figure 1). A summary of patient-, surgeon-, and treatment-related factors and their relation to major postoperative complications is presented in Table 2.

\section{DISCUSSION}

Despite a lack of randomized controlled data, conventional VATS as defined by the CALGB 39802 study has been established as the standard of care for patients with NSCLC, with $62 \%$ of lobectomies performed through the VATS approach in the recent STS GTSD. ${ }^{13-15}$ The superior postoperative outcomes and similar long-term oncologic outcomes of VATS lobectomy compared with open thoracotomy have been demonstrated in a number of systematic reviews and meta-analyses. ${ }^{16,17}$ More recently, robotic pulmonary resections have been performed in increasing numbers with encouraging outcomes at both community and tertiary centers within the United States, as well as internationally. ${ }^{4,11,18,19}$ A systematic review and meta-analysis comparing robotic pulmonary resections versus thoracotomy reported a trend toward fewer postoperative complications and shorter hospitalization after the robotic approach, but the available data at the time precluded conclusive findings. ${ }^{2}$ Given the relative paucity of robust clinical data on postoperative complications after robotic pulmonary resection, the 
TABLE 2. Univariate analysis of factors associated with major postoperative complications after robotic anatomic pulmonary resections for nonsmall cell lung cancer

\begin{tabular}{|c|c|c|c|c|}
\hline Characteristic & $\begin{array}{l}\text { All patients } \\
(\mathrm{n}=1264)\end{array}$ & $\begin{array}{l}\text { Major complication } \\
\quad(n=54 ; 4.3 \%) \\
\end{array}$ & $\begin{array}{c}\text { No major complication } \\
(\mathrm{n}=1210 ; 95.7 \%)\end{array}$ & $P$ value \\
\hline Age, yr, median (IQR) & $69(63-74)$ & $69(63.5-75)$ & $69(63-74)$ & .77 \\
\hline Male sex, n (\%) & $562(44.5)$ & $34(63.0)$ & $528(43.6)$ & .01 \\
\hline Pack-years, median (IQR) & $20(0-40)$ & $30(11.5-50)$ & $20(0-40)$ & .05 \\
\hline $\mathrm{ECOG} \geq 1, \mathrm{n}(\%)$ & $295(26.8)$ & $14(27.5)$ & $281(26.7)$ & .87 \\
\hline Redo operation, $\mathrm{n}(\%)$ & $43(3.4)$ & $3(5.6)$ & $40(3.3)$ & .43 \\
\hline BMI, median (IQR) & $26(23-30)$ & $26(24-29)$ & $26(23-30)$ & .95 \\
\hline $\begin{array}{l}\text { cStage, n (\%) } \\
\text { I } \\
\text { II } \\
\text { III } \\
\text { IV }\end{array}$ & $\begin{array}{c}937(74.2) \\
204(16.2) \\
109(8.6) \\
13(1.0)\end{array}$ & $\begin{array}{c}32(59.3) \\
14(25.9) \\
7(13.0) \\
1(1.9)\end{array}$ & $\begin{array}{l}905(74.9) \\
190(15.7) \\
102(8.4) \\
12(1.0)\end{array}$ & .09 \\
\hline Neoadjuvant therapy, n (\%) & $107(8.5)$ & $9(16.7)$ & $98(8.1)$ & .04 \\
\hline $\begin{array}{l}\text { Histopathology, n (\%) } \\
\text { Adeno } \\
\text { Squamous } \\
\text { Large cell } \\
\text { Carcinoid } \\
\text { Other }\end{array}$ & $\begin{array}{c}937(74.1) \\
154(12.2) \\
16(1.3) \\
80(6.3) \\
77(6.1)\end{array}$ & $\begin{aligned} 39 & (72.2) \\
8 & (14.8) \\
1 & (1.9) \\
1 & (1.9) \\
5 & (9.3)\end{aligned}$ & $\begin{array}{c}898(74.2) \\
146(12.1) \\
15(1.2) \\
79(6.5) \\
72(6.0)\end{array}$ & .52 \\
\hline $\begin{array}{l}\text { Tumor site, n (\%) } \\
\text { RUL } \\
\text { RML } \\
\text { RLL } \\
\text { LUL } \\
\text { LLL } \\
\text { RUL/RML } \\
\text { RML/RLL }\end{array}$ & $\begin{array}{c}435(34.4) \\
90(7.1) \\
244(19.3) \\
307(24.3) \\
168(13.3) \\
11(0.9) \\
8(0.6)\end{array}$ & $\begin{array}{c}15(27.8) \\
3(5.6) \\
14(25.9) \\
14(25.9) \\
5(9.3) \\
2(3.7) \\
1(1.9)\end{array}$ & $\begin{array}{c}420(34.7) \\
87(7.2) \\
230(19.0) \\
293(24.2) \\
163(13.5) \\
9(0.7) \\
7(0.6)\end{array}$ & .15 \\
\hline $\begin{array}{l}\text { Size of resection, n (\%) } \\
\text { Segmentectomy } \\
\text { Lobectomy } \\
\text { Bilobectomy } \\
\text { Pneumonectomy }\end{array}$ & $\begin{array}{c}102(8.1) \\
1134(89.7) \\
24(1.9) \\
4(0.3)\end{array}$ & $\begin{array}{c}4(7.4) \\
46(85.2) \\
3(5.6) \\
1(1.9)\end{array}$ & $\begin{array}{c}98(8.1) \\
1088(89.9) \\
21(1.7) \\
3(0.2)\end{array}$ & .04 \\
\hline $\mathrm{R} 0$ resection, $\mathrm{n}(\%)$ & $1249(98.8)$ & $54(100)$ & $1195(98.8)$ & 1.00 \\
\hline Duration of procedure, min, median (IQR) & $187(151-231)$ & $211(145-270.5)$ & $186.5(151-230)$ & .09 \\
\hline Blood loss, mL, median (IQR) & $50(25-100)$ & $50(25-100)$ & $50(25-100)$ & .74 \\
\hline $\begin{array}{l}\text { Surgeon experience } \leq 20 \text { cases } \\
\quad(\mathrm{n}=1263 ; 99.9 \%), \mathrm{n}(\%)\end{array}$ & $191(15.1)$ & $10(18.5)$ & $181(15.0)$ & .44 \\
\hline Hospitalization period, median (IQR) & $4(3-6)$ & $8.5(5-13)$ & $4(3-6)$ & $<.01$ \\
\hline ICU LOS $>1 \mathrm{~d}$ & $26(2.1)$ & $9(17.0)$ & $17(1.4)$ & $<.01$ \\
\hline
\end{tabular}

$\overline{I Q R}$, Interquartile range; $E C O G$, Eastern Cooperative Oncology Group; $B M I$, body mass index; $R U L$, right upper lobe; $R M L$, right middle lobe; $R L L$, right lower lobe; $L U L$, left upper lobe; $L L L$, left lower lobe; $I C U$, intensive care unit; $L O S$, length of stay.

present study aimed to identify their incidence and outcomes using a standardized database limited to major complications defined by the Clavien-Dindo classification system.

Key findings of the present study, described in Figure 2, included a relatively low incidence of major postoperative complications, at $4.3 \%$. This was comparable to historical outcomes of the CALGB 39802 study, which reported a $7.4 \%$ incidence of grade $\geq$ III postoperative complications, as well as more recent data from the STS GTSD, which reported $9.1 \% .^{13,20}$ However, it should be noted that specific grading of individual complications may have differed between the previous trials and the present study. The most common major complications identified in the 


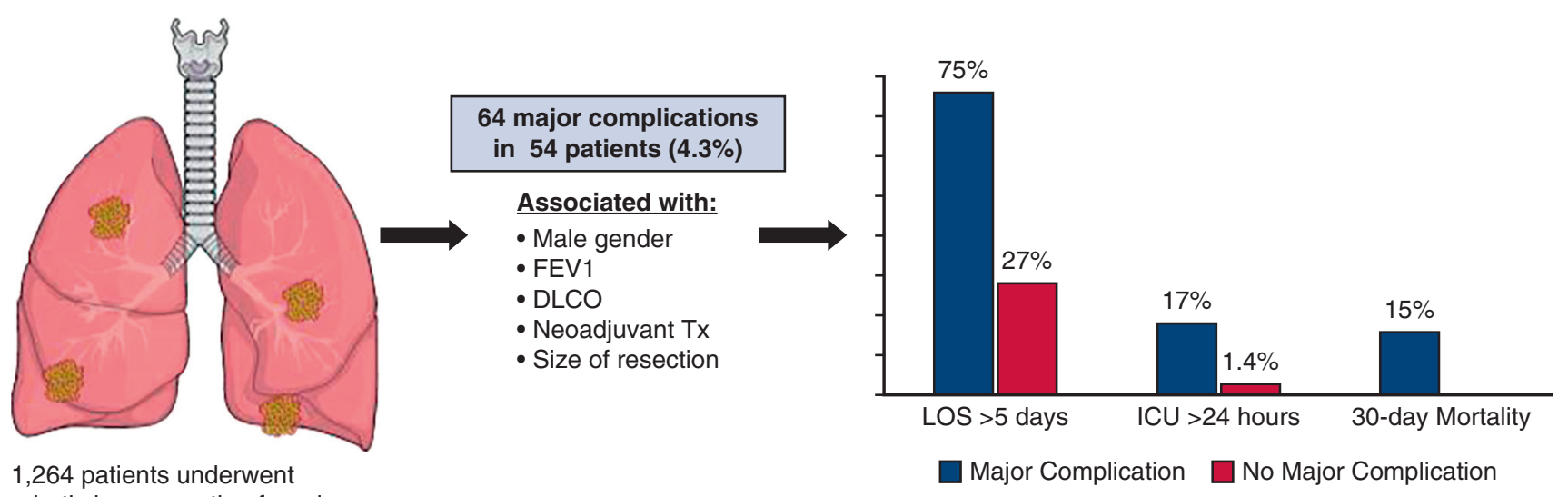

robotic lung resection for primary

lung cancer at four institutions.

FIGURE 2. The incidence of major postoperative complications in 1264 patients who underwent robotic lung resection for primary lung cancer, as well as the poor outcomes associated with major complications. $F E V_{1}$, Forced expiratory volume in 1 second; $D L C O$, diffusion capacity of carbon monoxide; $L O S$, length of stay; $I C U$, intensive care unit.

present report included pneumonia, prolonged air leak, atelectasis, ARDS, and atrial fibrillation, consistent with previous literature on VATS and robotic pulmonary resection. ${ }^{13,17,21,22}$ Univariate analysis identified male sex, $\mathrm{FEV}_{1}$, DLCO, extent of resection, and neoadjuvant therapy as associated with an increased risk for postoperative complications. Although the overall mortality rate for the entire cohort was relatively low at $0.6 \%$, patients who experienced a major postoperative complication had a $14.8 \%$ risk of postoperative death, as well as significantly longer hospital and ICU lengths of stay compared with patients without a major complication. Interestingly, the patient's age, performance status, and BMI were not associated with the presence of a major complication, contrary to previous findings from a prospective study of patients who underwent pulmonary resection by open thoracotomy. ${ }^{23}$ Potential explanations for these findings include a less traumatic robotic approach that can be better tolerated by older patients with worse performance status, as well as obese patients who may benefit more from minimally invasive incisions compared with an open thoracotomy. In addition, previous thoracic surgery on the ipsilateral side did not have a significant impact on major postoperative complications, contrary to patients who underwent thoracotomy and VATS within the STS GTSD, possibly indicating the advantages of RAL in performing adhesiolysis safely. ${ }^{15}$ In regard to the surgeon's previous operative experience, the present study found no differences in the incidence of major postoperative complications for $\leq 20$ cases versus $>20$ cases, although the former group was associated with longer duration of operation, similar to other contemporary reports. ${ }^{24}$

Limitations of the present multi-institutional study include its retrospective nature and the intrinsic potential biases and data heterogeneity associated with this study design. All the participating centers had a prospectively maintained database, and a standardized data form and a data dictionary were formulated after discussion and consensus a priori to centralized data collection. Owing to the length of the study period, robotic technology had evolved from the original models to the current $\mathrm{Xi}$ model (da Vinci; Intuitive Surgical, Sunnyvale, Calif). Other technical variations also existed among the institutions, and in some cases within an institution, regarding to the "total portal" versus "robotic-assisted" approach, as outlined by a proposed nomenclature system for robotic pulmonary procedures. ${ }^{25}$ However, there are limited data to demonstrate significantly different outcomes of these technical variations, and the heterogeneity within the database likely reflected the real-world experience among different centers. We also acknowledge that patients selected for robotic resections in the present study had relatively favorable pulmonary function results before surgery. However, there were no specific selection criteria common to all surgeons who participated in the study.

\section{CONCLUSIONS}

In summary, although the incidence of major postoperative complications after robotic pulmonary resection was found to be relatively low, these complications were associated with an increased risk of postoperative mortality and prolonged hospitalization. A number of patient- and treatment-related factors, such as male sex, poor $\mathrm{FEV}_{1}$ or DLCO, extensive resection, and neoadjuvant therapy, were found to be associated with major postoperative complications. Patients who were older, had a lower performance status, higher BMI, or underwent previous ipsilateral thoracic surgery were not at significantly higher risk for major postoperative 
complications. These patients may especially benefit more from a robotic approach compared with the open thoracotomy approach.

\section{Webcast}

You can watch a Webcast of this AATS meeting presentation by going to: https://aats.blob.core.windows. net/media/19\%20AM/Monday_May6/Mini\%20Theater/ Mini \%20Theater/MT\%20\%232\%20-\%20Thoracic $\% 20$ Mini\%20Oral\%20Competition/MT5_8_webcast_0113 22351.mp4.

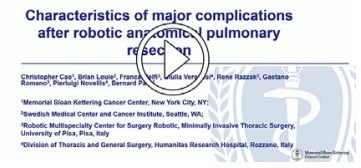

\section{Conflict of Interest Statement}

Dr Park had received personal fees from Intuitive Surgical. Dr Melfi is a proctor for Intuitive Surgical. Dr Veronesi is a proctor for ABI Medica and receives speaker honoraria and serves as a consultant for Medtronic and Johnson \& Johnson. Dr Louie holds a restricted research grant from Intuitive Surgical. All other authors have nothing to disclose with regard to commercial support.

\section{References}

1. Cerfolio RJ, Ghanim AF, Dylewski M, Veronesi G, Spaggiari L, Park BJ. The long-term survival of robotic lobectomy for non-small cell lung cancer: a multi-institutional study. J Thorac Cardiovasc Surg. 2018;155:778-86.

2. Cao C, Manganas C, Ang SC, Yan TD. A systematic review and meta-analysis on pulmonary resections by robotic video-assisted thoracic surgery. Ann Cardiothorac Surg. 2012;1:3-10.

3. Reddy RM, Gorrepati ML, Oh DS, Mehendale S, Reed MF. Robotic-assisted versus thoracoscopic lobectomy outcomes from high-volume thoracic surgeons. Ann Thorac Surg. 2018;106:902-8.

4. Adams RD, Bolton WD, Stephenson JE, Henry G, Robbins ET, Sommers E. Initial multicenter community robotic lobectomy experience: comparisons to a national database. Ann Thorac Surg. 2014;97:1893-8; discussion 1899-900.

5. Louie BE, Wilson JL, Kim S, Cerfolio RJ, Park BJ, Farivar AS, et al. Comparison of video-assisted-thorascopic-surgery and robotic approaches for clinical stage I and II non-small cell lung cancer using the Society of Thoracic Surgeons database. Ann Thorac Surg. 2016;102:917-24.

6. Rajaram R, Mohanty S, Bentrem DJ, Pavey ES, Odell DD, Bharat A, et al. Nationwide assessment of robotic lobectomy for non-small cell lung cancer. Ann Thorac Surg. 2017;103:1092-100.

7. Dindo D, Demartines N, Clavien PA. Classification of surgical complications: a new proposal with evaluation in a cohort of 6336 patients and results of a survey. Ann Surg. 2004;240:205-13.
8. Goldstraw P, Chansky K, Crowley J, Rami-Porta R, Asamura H, Eberhardt WE, et al. The IASLC Lung Cancer Staging Project: proposals for revision of the TNM stage groupings in the forthcoming (eighth) edition of the TNM Classification for Lung Cancer. J Thorac Oncol. 2016;11:39-51.

9. Gharagozloo F, Margolis M, Tempesta B, Strother E, Najam F. Robot-assisted lobectomy for early-stage lung cancer: report of 100 consecutive cases. Ann Thorac Surg. 2009;88:380-4.

10. Cheufou DH, Mardanzai K, Ploenes T, Theegarten D, Stamatis G, Kampe S, et al. Effectiveness of robotic lobectomy-outcome and learning curve in a high-volume center. Thorac Cardiovasc Surg. 2019;67:573-7.

11. Melfi FM, Mussi A. Robotically assisted lobectomy: learning curve and complications. Thorac Surg Clin. 2008;18:289-95. vi-vii.

12. Veronesi G, Agoglia BG, Melfi F, Maisonneuve P, Bertolotti R, Bianchi PP, et al. Experience with robotic lobectomy for lung cancer. Innovations (Phila). 2011;6: 355-60.

13. Swanson SJ, Herndon JE II, D'Amico TA, Demmy TL, McKenna RJ Jr, Green MR, et al. Video-assisted thoracic surgery lobectomy: report of CALGB 39802 - a prospective, multi-institution feasibility study. J Clin Oncol. 2007; 25:4993-7.

14. Cao C, Tian DH, Wolak K, Oparka J, He J, Dunning J, et al. Cross-sectional survey on lobectomy approach (X-SOLA). Chest. 2014;146:292-8.

15. Fernandez FG, Kosinski AS, Burfeind W, Park B, DeCamp MM, Seder C, et al. The Society of Thoracic Surgeons lung cancer resection risk model: higher quality data and superior outcomes. Ann Thorac Surg. 2016;102: 370-7.

16. Cao C, Manganas C, Ang SC, Peeceeyen S, Yan TD. Video-assisted thoracic surgery versus open thoracotomy for non-small cell lung cancer: a meta-analysis of propensity score-matched patients. Interact Cardiovasc Thorac Surg. 2013;16:244-9.

17. Yan TD, Black D, Bannon PG, McCaughan BC. Systematic review and meta-analysis of randomized and nonrandomized trials on safety and efficacy of video-assisted thoracic surgery lobectomy for early-stage non-small-cell lung cancer. J Clin Oncol. 2009;27:2553-62.

18. Veronesi G, Galetta D, Maisonneuve P, Melfi F, Schmid RA, Borri A, et al. Four-arm robotic lobectomy for the treatment of early-stage lung cancer. J Thorac Cardiovasc Surg. 2010;140:19-25.

19. Cerfolio RJ, Bryant AS, Skylizard L, Minnich DJ. Initial consecutive experience of completely portal robotic pulmonary resection with 4 arms. J Thorac Cardiovasc Surg. 2011;142:740-6.

20. Seder CW, Raymond DP, Wright CD, Gaissert HA, Chang AC, Clinton S, et al. The Society of Thoracic Surgeons General Thoracic Surgery Database 2017 update on outcomes and quality. Ann Thorac Surg. 2017; 103:1378-83.

21. Cao C, Manganas C, Ang SC, Yan TD. A meta-analysis of unmatched and matched patients comparing video-assisted thoracoscopic lobectomy and conventional open lobectomy. Ann Cardiothorac Surg. 2012;1:16-23.

22. Yang J, Xia Y, Yang Y, Ni ZZ, He WX, Wang HF, et al. Risk factors for major adverse events of video-assisted thoracic surgery lobectomy for lung cancer. Int J Med Sci. 2014;11:863-9.

23. Agostini P, Cieslik H, Rathinam S, Bishay E, Kalkat MS, Rajesh PB, et al. Postoperative pulmonary complications following thoracic surgery: are there any modifiable risk factors? Thorax. 2010;65:815-8.

24. Taniguchi Y, Nakamura H, Miwa K, Haruki T, Araki K, Takagi Y, et al. Initial results of robotic surgery for primary lung cancer: feasibility, safety and learning curve. Yonago Acta Med. 2017;60:162-6.

25. Abbas AE. New nomenclature for robotic-assisted thoracic surgery also gets rid of RATS. J Thorac Cardiovasc Surg. 2017;154:1070-1.

Key Words: robotic, anatomic pulmonary resection, major complications 